\title{
Non-neurologic complications following surgery for scoliosis
}

\author{
Hye Jeong Seo, Ha Jung Kim, Young-Jin Ro, and Hong-Seuk Yang \\ Department of Anesthesiology and Pain Medicine, Asan Medical Center, College of Medicine, University of Ulsan, Seoul, Korea
}

Background: The purpose of this study was to determine the prevalence of non-neurologic complications following surgery for scoliosis and to identify factors that can increase this risk.

Methods: The demographic data, medical and surgical histories, and prevalence of non-neurologic complications were reviewed in a retrospective cohort of 602 patients, who had undergone corrective surgery for scoliosis between January 2001 and June 2011.

Results: There were 450 patients under 20 years old (U20) and 152 of patients above 20 years old (A20) enrolled in this study. Forty-nine patients in U20 (10.9\%) and 18 patients in A20 (11.8\%) had post-operative complications. Respiratory complications were most common in U20 (4\%) and gastrointestinal complications were most common in A20 (7\%). There was no significant difference between the 2 groups in the prevalence of complications. Logistic regression revealed that factors that correlated with an increased odds for complications were Cobb angle $(\mathrm{P}=0.001 /$ $\mathrm{P}=0.013$, respectively), length of operation time $(\mathrm{P}=0.003 / \mathrm{P}=0.006$, respectively $)$, duration of anesthesia $(\mathrm{P}<0.001 /$ $\mathrm{P}=0.005$, respectively) and transfusion $(\mathrm{P}=0.003 / \mathrm{P}=0.015$, respectively $)$ in $\mathrm{U} 20$ and A20. Also, comorbidities ( $\mathrm{P}$ $=0.021)$ in $\mathrm{U} 20$, and decreased body mass index $(\mathrm{P}=0.030)$, pre-operative forced vital capacity $(\mathrm{P}=0.001)$, forced expired volume in 1s $(\mathrm{P}=0.001)$, increased numbers of vertebrae fused $(\mathrm{P}=0.004)$, blood loss $(\mathrm{P}=0.001)$ in A20 were associated with increased odds for complications.

Conclusions: There was no difference in the prevalence of complication in scoliosis patients by age. The prevalence of complication was dependent on Cobb angle, length of operation time, duration of anesthesia and transfusion of PRBC. Deterioration of preoperative pulmonary function significantly increased risk of post-operative complications in adult patients. (Korean J Anesthesiol 2013; 64: 40-46)

Key Words: Anesthesia, Non-neurologic complication, Scoliosis.

Received: February 6, 2012. Revised: 1st, March 10, 2012; 2nd, May 2, 2012. Accepted: May 14, 2012.

Corresponding author: Hong-Seuk Yang, M.D., Ph.D., Department of Anesthesiology and Pain Medicine, Asan Medical Center, College of Medicine, University of Ulsan, 88, Olympic-ro 43-gil, Songpa-gu, Seoul 138-736, Korea. Tel: 82-2-3010-3865, Fax: 82-2-470-1363, E-mail: hsyang@amc.seoul.kr

(c) This is an open-access article distributed under the terms of the Creative Commons Attribution Non-Commercial License (http:// creativecommons.org/licenses/by-nc/3.0/), which permits unrestricted non-commercial use, distribution, and reproduction in any medium, provided the original work is properly cited. 


\section{Introduction}

Scoliosis is a spinal deformity in which the spine is twisted and is curved abnormally, causing sternal deformity and consequently, trunkal deformity [1]. Of the various types of scoliosis, idiopathic scoliosis is the most common, occurring in $1-3 \%$ of adolescents aged $10-16$ years [2].

Spinal corrective surgery involves heavy intra-operative hemorrhage and frequent intra and post-operative complications. In particular, patients who have undergone corrective surgery to treat scoliosis, have $0-10 \%$ incidence of nonneurological complications [3]. Studies on complications that occurred during or after corrective surgery for scoliosis reported that the length of operation time, duration of anesthesia, intraoperative bleeding volume, and types of surgical procedure influenced the occurrence of complications [3]. In patients with neuromuscular scoliosis who had had concomitant moderate or severe pulmonary dysfunction before surgery, the incidence of respiratory complications was higher [4].

Pediatric patients who are undergoing scoliosis corrective surgery have features that differ from those of adult patients who are undergoing the same type of surgery [5]. First, scoliosis in pediatric patients is generally a spinal deformity caused by neurofibromatosis, and is largely the result of Marfan syndrome [6]. Second, spinal corrective surgery is performed in pediatric patients to prevent the progression of deformity. In adults, however, spinal corrective surgery is performed to relieve pain, as degenerative change is the cause of spinal deformity $[5,7]$. Third, spinal curvature and deformity in pediatric patients differ from those in adults; and for pediatric patients, radiographic correction is more effective [5]. Fourth, scoliosis causes little to no pain in pediatric patients, whereas pain improvement is the desired outcome in adults [5]. Because of these features, it is considered that the incidence of complications after scoliosis corrective surgery can be influenced by various factors. There are still dissenting views, however, regarding the incidence of complications by age $[3,4]$.

In previous studies on scoliosis, the ages of adult patients varied from 18 years, [8,9] to $19[6,7], 20[5], 21[1]$, and 30 years [10], however patient inclusion criteria was not uniform among these trials. In this study, however, 20 years of age was used as the criterion for distinguishing between children and adults, according to a study on the correlation between age and prognosis, where the incidence of complications increased in patients aged 20 years or older [11].

This study aimed to examine the preoperative features of pediatric and adult patients who were undergoing spinal corrective surgery, and to analyze their postoperative complications.

\section{Materials and Methods}

This study was performed upon the approval of this hospital's Internal Review Board. Patients who had been diagnosed with scoliosis and then had undergone spinal corrective surgery at this hospital within the period of 1 January 2001 to 30 June 2011 were included in this study. The patients were divided into 2 groups based on their age at the time of their surgery, the below 20 years old group (U20) and the more than 20 years old group (A20). The 2 groups were further divided into patients $<20$ years old with complications group (U20C), patients $<20$ years old without complications group (U20N), patients $>20$ years old with complications group (A20C), and patient $>20$ years old without complications group (A20N). Data were collected retrospectively from medical records, and included the preoperative diagnosis, age, weight, pre-operative condition, intra and post-operative records, and test results. All the patients underwent pre-operative electrocardiography and chest radiography, and all but 35 patients who were mentally retarded and had low compliance underwent a pre-operative pulmonary function test using spirometry. Patients with concomitant congenital heart disease underwent pre-operative echocardiography, the outcomes of which were evaluated by pediatric cardiology specialists.

For anesthetic induction, pentothal sodium $(3-5 \mathrm{mg} /$ $\mathrm{kg}$ ) or propofol $(2 \mathrm{mg} / \mathrm{kg})$ was used with rocuronium $(0.6$ $\mathrm{mg} / \mathrm{kg})$ or vecuronium $(0.1 \mathrm{mg} / \mathrm{kg})$ as a muscle relaxant. To maintain anesthesia, total intravenous anesthesia (TIVA) using remifentanil and propofol, or inhalation anesthesia, was performed.

Complications were classified into one of the following complications: respiratory, cardiovascular, gastrointestinal, and 'other. Respiratory complications included atelectasis, pneumothorax, hemothorax, pleural effusion, pulmonary edema or congestion, and pneumonia; and cardiovascular complications included arrhythmia, hypotension, and heart failure. Atelectasis was defined as a condition in which hypoxia led to a prolonged hospital stay or in which bronchoscope-assisted treatment was required. Pleural effusion was defined as a condition requiring an additional chest tube insertion. Pulmonary edema or congestion was defined as a condition wherein endotracheal intubation was performed or additional ICU treatment was provided due to symptoms such as dyspnea. Pneumonia was defined as a condition requiring antibiotic treatment. Hypotension was defined as a systolic blood pressure (BP) of $80 \mathrm{mmHg}$ or less, and although such routine treatments as vasopressor, vasoconstrictor, and fluid therapy were performed without a response in $\mathrm{BP}$; and the $\mathrm{BP}$ of $80 \mathrm{mmHg}$ or less was observed twice or more in consecutive 5-minute intervals. Heart failure was defined as a condition in which the criteria for 
grade 3 or higher symptoms of adverse events (CTCAE, v 4.03) were so severe that daily activities were impossible, even during the resting phase, and treatment was required. Gastrointestinal complications included ileus, pseudomembranous colitis, and an increased hepatic enzyme level. Ileus was defined as a condition that had been diagnosed by the digestive medicine department of this hospital based on clinical symptoms and abdominal radiography, and a CTCAE (v 4.03) grade 3 or above. Pseudomembranous colitis was defined as the condition confirmed by colonoscopy. An increased hepatic enzyme level was defined as a CTCAE (v 4.03) of grade 2 or above, and the aspartic acid transaminase (AST)/alanine transaminase (ALT) levels were 3 or more times higher than normal levels.

Other complications included surgical site infection, transfusion reaction, and vocal cord injury. Surgical site infection was defined as a condition requiring antibiotic treatment and surgery. Transfusion reaction was defined as systemic hives that occurred immediately after surgery, which required treatment for angioedema. Vocal cord injury was diagnosed by an otolaryngologist.

Data were presented as means and standard deviations or numbers of patients. Comparisons between U20 and A20, the Chi-square test or a Fisher's exact test was used for binary variables and a student t-test was performed for continuous data. Logistic regression analysis was performed to determine if there was a correlation between variables and a prevalence of complications. Data were analyzed using SPSS 19.0, and the statistical significance level was set at $\mathrm{P}$ value $<0.05$.

\section{Results}

Overall, there were 602 patients who met the criteria and were enrolled into this study. Among these patients, 450 (74.8\%) belonged to group U20, and 152 (25.2\%), to group A20. The BMI was significantly higher in group A20 than in group U20 (23.0 \pm 5.1 vs. $\left.19.5 \pm 4.2 \mathrm{~kg} / \mathrm{m}^{2} ; \mathrm{P}<0.001\right)$. In addition, Group A20 also had significantly more comorbidities than in group U20 (39 vs. $20 \%$; $\mathrm{P}<0.001)$. According to the preoperative diagnoses in group U20, idiopathic scoliosis was the major disease type (80.4\%). In group A20, degenerative scoliosis was the major disease type (52.7\%). The pre-operative Cobb angle was statistically significantly greater in group U20 than in group A20 $\left(59.0 \pm 15.9\right.$ vs. $\left.42.7 \pm 19.5^{\circ} ; \mathrm{P}<0.001\right)$. According to the results of the pulmonary function test, FVC ratio and FEV1 ratio were statistically significantly greater in group A20 than in group U20. However, the FEV1/FVC ratio was statistically significantly greater in group U20 than in group A20 (89.7 \pm 6.7 vs. $84.2 \pm$ 8.3\%; $\mathrm{P}<0.001)$. The number of fused vertebrae was greater in group U20 than in group A20 (9.6 \pm 2.1 vs. $6.4 \pm 3.6$; P $<0.001)$. The lenth of operating time was significantly longer in group
A20 than in group U20 (286.5 \pm 76.6 vs. $263.4 \pm 55.1 \mathrm{~min}$; $\mathrm{P}<$ 0.001). The duration of anesthesia was also significantly longer in group A20 (342.2 \pm 83.9 vs. $315.8 \pm 63.2 \mathrm{~min} ; \mathrm{P}<0.001)$. The intra-operative blood loss was significantly greater in group A20 than in group $\mathrm{U} 20(2,855.8 \pm 1,822.9$ vs. $1,941.6 \pm 1,279.3 \mathrm{ml} ; \mathrm{P}<$ 0.001) (Table 1).

Respiratory complications were most common in group U20 (4\%) and gastrointestinal complications were most common in group A20 (7\%). There was no significant difference between the 2 groups in prevalence of complications. The only significant difference between the groups was the post-operative hospital stay. The group A20 stayed in hospital longer than group U20 (11.8 \pm 5.3 vs. $9.0 \pm 3.9$ days; $\mathrm{P}<0.001$ ) (Table 2 ).

Univariate logistic regression showed that comorbidities (Odds ratio [OR], 2.14; 95\% confidence interval [CI], 1.12-4.1; $\mathrm{P}=0.021)$, increased Cobb angle (OR, 1.03; CI, 1.01-1.04; $\mathrm{P}$ $=0.001)$, operation time $(\mathrm{OR}, 1.01 ; \mathrm{CI}, 1.00-1.04 ; \mathrm{P}=0.003)$,

Table 1. Clinical Characteristics of Study Patients

\begin{tabular}{|c|c|c|}
\hline & $\mathrm{U} 20(\mathrm{n}=450)$ & $\mathrm{A} 20(\mathrm{n}=152)$ \\
\hline \multicolumn{3}{|l|}{ Pre-operative } \\
\hline Age (yr) & $13.9 \pm 2.5$ & $45.2 \pm 19.9$ \\
\hline Sex (female) & $343(76)$ & $125(82)$ \\
\hline Weight (kg) & $47.8 \pm 11.9$ & $57.2 \pm 9.5^{*}$ \\
\hline Height (cm) & $156.2 \pm 13.6$ & $158.5 \pm 8.3^{*}$ \\
\hline $\mathrm{BMI}\left(\mathrm{kg} / \mathrm{m}^{2}\right)$ & $19.5 \pm 4.2$ & $23.0 \pm 5.1 *$ \\
\hline Comorbidities & $90(20)$ & $60(39) *$ \\
\hline \multicolumn{3}{|l|}{ Diagnosis } \\
\hline Congenital & $43(9.6)$ & $6(3.9) *$ \\
\hline Idiopathic & $362(80.4)$ & $56(36.8) *$ \\
\hline Degenerative & $0(0)$ & $80(52.7)^{*}$ \\
\hline Marfan syndrome & $8(1.8)$ & $0(0)$ \\
\hline Neuromuscular & $25(5.5)$ & $8(5.3)$ \\
\hline Neurofibromatosis & $12(2.7)$ & $2(2.3)$ \\
\hline Cobb angle $\left({ }^{\circ}\right)$ & $59.0 \pm 15.9$ & $42.7 \pm 19.5^{*}$ \\
\hline \multicolumn{3}{|l|}{ PFT } \\
\hline \%predict FVC & $83.2 \pm 17.7$ & $88.9 \pm 19.5^{*}$ \\
\hline \%predict FEV1 & $79.0 \pm 19.1$ & $94.4 \pm 25.7^{*}$ \\
\hline FEV1/FVC (\%) & $89.7 \pm 6.7$ & $84.2 \pm 8.3^{*}$ \\
\hline Pre-operative $\mathrm{Hb}$ (g/dl) & $13.4 \pm 1.2$ & $13.3 \pm 1.2$ \\
\hline \multicolumn{3}{|l|}{ Intra-operative } \\
\hline \multicolumn{3}{|l|}{ Operation name } \\
\hline ASF & $5(1)$ & $1(1)$ \\
\hline PSF & 444 (99) & $151(99)$ \\
\hline OSAPSF & $1(0)$ & $0(0)$ \\
\hline No. of segments fused & $9.6 \pm 2.1$ & $6.4 \pm 3.6^{*}$ \\
\hline Operation time (min) & $263.4 \pm 55.1$ & $286.5 \pm 76.6^{*}$ \\
\hline Anesthetic time (min) & $315.8 \pm 63.2$ & $342.2 \pm 83.9 *$ \\
\hline $\mathrm{EBL}(\mathrm{ml})$ & $1,941.6 \pm 1,279.3$ & $2,855.8 \pm 1,822.9 *$ \\
\hline PRBC transfusion & $4.4 \pm 3.4$ & $5.1 \pm 4.4$ \\
\hline
\end{tabular}

Data are reported as mean \pm SD or number (\%). U20: under 20 years old. A20: above 20 years. BMI: body mass index. PFT: pulmonary function test. FVC: forced vital capacity. FEV1: forced expired volume in $1 \mathrm{~s}$. Hb: hemoglobin. ASF: anterior spinal fusion. PSF: posterior spinal fusion. OSAPSF: one step anterior and posterior spinal fusion. EBL: estimated blood loss. ${ }^{*} \mathrm{P}<0.05$, compared with group U20. 
duration of anesthesia (OR, 1.01; CI, 1.00-1.01; P $<0.001)$, and PRBC transfusion (OR, 1.12; CI, 1.04-1.20; $\mathrm{P}=0.003$ ) increased the odds for complication in group U20 (Table 3). In group A20, univariate logistic regression showed that a higher BMI (OR, 0.84; CI, 0.72-0.98; $\mathrm{P}=0.030$ ), FVC ratio (OR, 0.95; CI, 0.92-0.98; $\mathrm{P}=0.001$ ) and FEV1 ratio (OR, 0.96; CI, 0.94-0.98; $\mathrm{P}=0.001)$ lowered those odds, while increased Cobb angle (OR, 1.03; CI, 1.01-1.06; $\mathrm{P}=0.013$ ), operation time (OR, 1.01;

Table 2. Patient Outcomes

\begin{tabular}{lcc}
\hline & $\mathrm{U} 20(\mathrm{n}=450)$ & $\mathrm{A} 20(\mathrm{n}=152)$ \\
\hline Complications & $49(11)$ & $18(12)$ \\
Respiratory & $19(4)$ & $5(3)$ \\
Pleural effusion & 11 & 1 \\
Pulmonary congestion/edema & 3 & 4 \\
Pneumothorax/hemothorax & 2 & 0 \\
Pneumonia & 1 & 0 \\
Atelectasis & 2 & 0 \\
Cardiovascular & $5(1)$ & $4(3)$ \\
Arrhythmia & 2 & 0 \\
Hypotension & 2 & 4 \\
Congestive heart failure & 1 & 0 \\
Gastrointestinal & $15(3)$ & $10(7)$ \\
Ileus & 9 & 6 \\
Pseudomembranous colitis & 1 & 0 \\
Elevated LFT & 5 & 4 \\
Others & $12(3)$ & $3(2)$ \\
Death & $1(0)$ & $0(0)$ \\
ICU stay (days) & $0.1 \pm 0.4$ & $0.1 \pm 0.4$ \\
Delayed extubation & $12(3)$ & $6(4)$ \\
Postoperative hospital stay (days) & $9.0 \pm 3.9$ & $11.8 \pm 5.3 *$ \\
\hline
\end{tabular}

Data are reported as mean \pm SD or number (\%). U20: under 20 years old. A20: above 20 years. LFT: liver function test, ICU: intensive care unit. ${ }^{*} \mathrm{P}<0.05$, compared with U20.
CI, 1.00-1.02; $\mathrm{P}=0.006)$, duration of anesthesia (OR, 1.01; CI, $1.00-1.01 ; \mathrm{P}=0.005)$, number of vertebrae fused (OR, 1.26; $\mathrm{CI}$, 1.07-1.47; P = 0.004), PRBC transfusion (OR, 1.29; CI, 1.05-1.57; $\mathrm{P}=0.015)$, and intra-operative blood loss (OR, 1.44; CI, 1.151.80; $\mathrm{P}=0.001$ ) were associated with increased odds (Table 4 ).

\section{Discussion}

In the patients who had undergone corrective surgery to treat scoliosis, the BMI, pre-operative pulmonary function test results, Cobb angle, number of fused vertebrae, operating time, and intra-operative blood loss differed by age, but the incidence and types of post-operative complications did not differ by age. In both the pediatric and adult patients, the Cobb angle and the amount of transfused concentrated red blood cells were related to the incidence of complications. The pre-operative decreased pulmonary function led to an increased incidence of complications in A20, but was not related to the incidence of complications in U20.

Takahashi et al. [5] reported that older patients who had undergone corrective scoliosis surgery were, the stiffer the spinal curvature was, which made correction even more difficult; and Nachemson [12] reported that adult patients who had concomitant thoracic scoliosis had increased risks of post-operative complications and death because of cardiopulmonary dysfunction. In addition, Anderson et al. [11] reported that of the patients aged 1-34 years who had undergone spinal surgery, those who had undergone the surgery when they were more than 20 years old had a higher incidence of post-operative pulmonary complications. In addition, Patil et al. [13] reported that pediatric patients (aged $0-17$ years) had a better short-

Table 3. Clinical Characteristics and Outcomes of Patients under 20 Years Old with or without Complications

\begin{tabular}{|c|c|c|c|}
\hline & $\mathrm{U} 20 \mathrm{~N}(\mathrm{n}=401)$ & $\mathrm{U} 20 \mathrm{C}(\mathrm{n}=49)$ & OR $(95 \% \mathrm{CI})$ \\
\hline \multicolumn{4}{|l|}{ Pre-operative } \\
\hline Weight (kg) & $48.1 \pm 11.8$ & $45.8 \pm 12.5$ & $0.98(0.96-1.01)$ \\
\hline Height (cm) & $156.6 \pm 12.8$ & $152.7 \pm 18.9$ & $0.98(0.96-1.00)$ \\
\hline $\mathrm{BMI}\left(\mathrm{kg} / \mathrm{m}^{2}\right)$ & $19.5 \pm 3.9$ & $19.8 \pm 5.9$ & $1.02(0.95-1.09)$ \\
\hline Comorbidities & $74(18 \%)$ & $16(33 \%)$ & $2.14(1.12-4.1) *, \dagger$ \\
\hline \multicolumn{4}{|l|}{ PFT } \\
\hline \%predict FVC & $83.4 \pm 17.4$ & $82.0 \pm 20.0$ & $1.00(0.98-1.01)$ \\
\hline \%predict FEV1 & $79.3 \pm 19.1$ & $76.4 \pm 19.0$ & $0.99(0.97-1.01)$ \\
\hline FEV1/FVC (\%) & $89.9 \pm 6.6$ & $88.1 \pm 7.2$ & $0.96(0.92-1.01)$ \\
\hline Cobb angle $\left({ }^{\circ}\right)$ & $58.0 \pm 15.0$ & $66.6 \pm 20.8$ & $1.03(1.01-1.04)^{*, \dagger}$ \\
\hline \multicolumn{4}{|l|}{ Intra-operative } \\
\hline Operation time (min) & $260.6 \pm 52.6$ & $286.2 \pm 69.2$ & $1.01(1.00-1.04)^{*, \dagger}$ \\
\hline Anesthetic time (min) & $312.1 \pm 59.6$ & $345.6 \pm 81.9$ & $1.09(1.00-1.01)^{*, \dagger}$ \\
\hline No. of segments fused & $9.5 \pm 2.0$ & $10.0 \pm 2.3$ & $1.12(0.96-1.31)$ \\
\hline PRBC transfusion $(\times 400 \mathrm{ml})$ & $4.3 \pm 3.2$ & $5.9 \pm 4.8$ & $1.12(1.04-1.20)^{*, \dagger}$ \\
\hline $\mathrm{EBL}(\mathrm{ml})$ & $1,950.4 \pm 1,321.0$ & $1,886.4 \pm 1,809.1$ & $1.26(0.92-1.72)$ \\
\hline
\end{tabular}

Data are reported as mean \pm SD or number (\%). U20N: under 20 years oll without complication. U20C: unfer 20 years old with complications, OR: Odds ratio, CI: confidence interval, BMI: body mass index, PFT: pulmonary function test, FVC: forced vital capacity, FEV1: forced expired volume in $1 \mathrm{~s}$, PRBC: packed red blood cell, EBL: estimated blood loss. *Statistically significant, $\mathrm{P}<0.05 .{ }^{\dagger}$ Factors that increase odds. 
Table 4. Clinical Characteristics and Outcomes of Patients above 20 Years Old with or without Complications

\begin{tabular}{|c|c|c|c|}
\hline & $\mathrm{A} 20 \mathrm{~N}(\mathrm{n}=134)$ & A20C $(n=18)$ & OR $(95 \% \mathrm{CI})$ \\
\hline \multicolumn{4}{|l|}{ Pre-operative } \\
\hline Weight (kg) & $57.8 \pm 9.4$ & $52.7 \pm 9.6$ & $0.94(0.89-1.00)$ \\
\hline Height (cm) & $158.4 \pm 8.2$ & $159.3 \pm 9.1$ & $1.01(0.96-1.07)$ \\
\hline $\operatorname{BMI}\left(\mathrm{kg} / \mathrm{m}^{2}\right)$ & $23.3 \pm 5.2$ & $20.8 \pm 3.7$ & $0.84(0.72-0.98)^{*, \neq}$ \\
\hline Comorbidities & $51(38 \%)$ & $9(50 \%)$ & $1.63(0.61-4.37)$ \\
\hline \multicolumn{4}{|l|}{ PFT } \\
\hline \%predict FVC & $91.0 \pm 1.01$ & $73.3 \pm 22.6$ & $0.95(0.92-0.98)^{*, \neq}$ \\
\hline \%predict FEV1 & $97.2 \pm 24.7$ & $73.3 \pm 23.4$ & $0.96(0.94-0.98)^{*} \neq$ \\
\hline FEV1/FVC (\%) & $84.3 \pm 8.1$ & $83.7 \pm 10.2$ & $0.99(0.93-1.05)$ \\
\hline Cobb angle $\left({ }^{\circ}\right)$ & $41.2 \pm 18.7$ & $54.2 \pm 21.4$ & $1.03(1.01-1.06)^{*, \dagger}$ \\
\hline \multicolumn{4}{|l|}{ Intra-operative } \\
\hline Operation time (min) & $280.1 \pm 72.7$ & $334.3 \pm 89.6$ & $1.01(1.00-1.02)^{*, \dagger}$ \\
\hline Anesthetic time (min) & $335.0 \pm 79.1$ & $396.1 \pm 100.8$ & $1.01(1.00-1.01)^{*, \dagger}$ \\
\hline No. of segments fused & $6.1 \pm 3.5$ & $8.8 \pm 3.5$ & $1.26(1.07-1.47) *,+$ \\
\hline PRBC transfusion $(\times 400 \mathrm{ml})$ & $4.4 \pm 3.4$ & $10.2 \pm 7.1$ & $1.29(1.05-1.57)^{*, \dagger}$ \\
\hline $\operatorname{EBL}(\mathrm{L})$ & $2.8 \pm 1.9$ & $3.2 \pm 1.7$ & $1.44(1.15-1.80)^{*, \dagger}$ \\
\hline
\end{tabular}

Data are reported as number (\%) or mean \pm SD. A20N: above 20 years old without complications, A20C: above 20 years old with complications, BMI: body mass index, OR: Odds ratio, CI: confidence interval. *Statistically significant, $\mathrm{P}<0.05 .{ }^{\dagger}$ Factors that increase odds. ${ }^{\ddagger}$ Factors that decrease odds.

term prognosis after corrective spinal surgery than adult patients. In this study, the incidence and types of complications did not differ between the U20 and A20. In A20, however, the post-operative hospital stay was significantly longer; and although the Cobb angle and the number of fused vertebrae were greater in U20, the operating time and the intra-operative blood loss were higher in A20. The absence of differences between the 2 groups in this study is believed to be because the overall incidence of complications was low (11\%), and the total size of A20 was small, with only 152 patients.

Regarding the relationship between the Cobb angle and the post-operative complications, Gibson [14] reported that at a Cobb angle of $65^{\circ}$ or more, the pulmonary volume decreased and disharmony between the ventilation and perfusion occurred; and a Cobb angle of above $100^{\circ}$ resulted in pulmonary hypertension and right ventricle hypertrophy. Kang et al. [4] also reported that a Cobb angle of $69^{\circ}$ or more resulted in increased post-operative pulmonary complications and the need for mechanical ventilation. On the other hand, Modi et al. [15] reported that the extent of spinal deformity did not increase with the incidence of post-operative complications and the risk of ICU treatment. In this study, the increased Cobb angle resulted in an increased risk of post-operative complications in both groups. But, of the 15 patients with a Cobb angle of $100^{\circ}$ or more, no patient experienced respiratory complications and one patient died as a result of a myocardial infarction during surgery. These might have been because physical therapy was performed for several months before the surgery on the patients with a pre-operative Cobb angle of $100^{\circ}$ or more to reduce the angle, and pediatric clinicians and rehabilitation medicine clinicians were fully aware of the related risks and thus, paid attention.

Of the risk factors of the occurrence of complications after scoliosis corrective surgery, the influence of the pre-operative pulmonary function test on the occurrence of post-operative complications is still debatable. Udink ten Cate et al. [16] reported that in patients with neuromuscular scoliosis, the preoperative pulmonary function test was a useful predictor, and vital capacity (VC) was a particularly important predictor of the need for post-operative mechanical ventilation. Yuan et al. [17] also reported that the pre-operative pulmonary function test was a prognostic factor that increased the need for postoperative mechanical ventilation in pediatric patients with scoliosis. On the other hand, Wazeka et al. [1] reported that of 21 patients with severe restrictive pulmonary dysfunction, only 4 patients required long-term mechanical ventilation; and Marsh et al. [18] reported that in 30 patients with neuromuscular scoliosis, there was no difference between the post-operative complications of the group with a VC of $30 \%$ or more and the group with a VC of less than $30 \%$. Harper et al. [19] reported that in 45 patients with Duchenne's muscular dystrophy, there was no difference between the complications of the group with an FVC ratio of less than $30 \%$ and the group with an FVC ratio of $30 \%$ or more. Whether or not the pre-operative decreased pulmonary function is a risk factor of post-operative complications in patients with idiopathic scoliosis remains debatable [20,21]. In this regard, Kang et al. [4] reported that the controversy on the impact of the pulmonary function test on the occurrence of complications was due to the low incidence of complications in patients with scoliosis. In this 
study, decreased pulmonary function did not increase the incidence of complications in pediatric patients, but influenced the occurrence of complications in adult patients. In this study, risk factors of respiratory complications could not be identified because of limitations in the statistical significance, as the overall incidence of complications was $11 \%$, and only $18(11.8 \%)$ of the 152 patients aged 20 years or more had complications, with only 5 patients having respiratory complications. Additional studies are required that include a higher number of patients with respiratory complications.

Smith et al. [22] reported that pediatric patients who had undergone scoliosis surgery and had a lower BMI, the greater the risk of superior mesenteric artery (SMA) syndrome. Hassan et al. [23] reported that in 106 patients who had undergone scoliosis surgery, the lower the BMI, the higher the blood transfusion amount required. In contrast, Chen et al. [10] reported that in adults, the higher the BMI, the higher the occurrence of spinal deformity and the greater the postoperative pain, although the higher BMI did not increase the incidence of post-operative complications. In this study, the SMA syndrome occurred in 2 patients, but the BMIs between U20N and U20C did not differ; and in the adult patients, a decreased BMI increased the incidence of complications. It is believed that the results of this study differed from those of Chen et al. [10] because a low BMI reflected a poor nutrition state rather than an increased BMI reflecting obesity.

In the pediatric patients with scoliosis, those who had comorbidites showed an increased incidence of complications. Taggart et al. [8] reported that although posterior spondylodesis is safe in most patients aged less than 18 years with congenital heart disease, those with concomitant severe pulmonary hypertension are at an increased risk of death. Bitan et al. [24] reported that of 44 patients with congenital heart disease who had undergone spondylodesis, one patient died during the surgery and one patient had an intra-operative cardiac arrest, but was resuscitated via cardiopulmonary resuscitation. Coran et al. [25] reported that of 74 patients with congenital heart disease, 2 died and $24 \%$ had complications. In this study, one patient with congenital heart disease had pre-operative concomitant mild pulmonary hypertension, and at day 1 postoperatively, experienced decreased blood pressure, increased pulmonary arterial blood pressure, and heart failure.

There were 12 patients had mental retardation, of whom 2 showed concomitant cerebral palsy. Wongprasartsuk and Stevens [26] reported that in cases of anesthesia administration in patients with cerebral palsy, communication difficulty and musculoskeletal-abnormality-related difficulty may occur; and that with the use of a muscle relaxant, problems such as increased sensitivity to succinylcholine, resistance to vecuronium, minimal alveolar concentration of an inhalation anesthetic agent, and difficulty in postoperative extubation. In this study, rocuronium and vecuronium were used as a muscle relaxant, and no related problems were observed. One patient with cerebral palsy died during surgery; and a second patient with an endotracheal tube in place was transferred to the ICU and the tube was removed later in the ICU without specific complications.

Since Sunohara et al. [27] reported in 1984 on scoliosis and malignant hyperthermia, numerous cases of malignant hyperthermia that occurred in patients with scoliosis had been reported [28]. Since 2008, in this study, TIVA has been performed using propofol and remifentanil. TIVA lowered the risk of malignant hyperthermia and enabled intra-operative identification of neural damage by enabling monitoring of somatosensory-evoked potential and motor-evoked potential $[29,30]$. The intra-operative effect site concentrations of propofol and remifentanil were $2.5-3.0 \mu \mathrm{g} / \mathrm{ml}$ and $15-20 \mathrm{ng} /$ $\mathrm{ml}$, respectively, with target-controlled infusion.

In one patient with neuromuscular scoliosis caused by cerebral palsy who died of post-operative complications, acute myocardial infarction occurred during the course of the spinal correction. Of the patients with cardiovascular complications, 2 transiently developed atrial fibrillation after the surgery but had a normal electrocardiograph within 1 hour. The 9 patients with gastrointestinal complications, whose AST and ALT levels were 3 times or more than the normal level, were diagnosed with hepatitis caused by a non-steroidal anti-inflammatory agent. Of the total 602 patients, 18 patients were transferred to the ICU with an endotracheal tube in place and 7 patients developed respiratory complications. Two patients developed respiratory complications due to intra-operative pneumothorax and hemothorax, and another 5 developed respiratory complications due to a large intra-operative transfusion, pulmonary edema caused by heavy bleeding, or hemodynamic instability. An additional 9 patients were transferred to the ICU with an endotracheal tube in place because they were diagnosed with severe restrictive ventilatory defect in the pre-operative pulmonary function test or because the removal of the tube was deferred due to severe mental retardation; in all of these patients, the endotracheal tube was removed within 2 hours.

This study had limitations in its regression analysis because of the low incidence of complications, and thus, we couldn't identify all significant variables of the univariate regression analysis were independent risk factors for post-operative complications. In addition, the correlation between each risk factor and the pulmonary or cardiovascular complications could not be identified. Regarding this, further studies with additional data are required. Also, there may have been some missing data among the hospital and clinical charts. Last, this was a retrospective study and the results are compromised as 
a result of relatively limited sample and a non-randomized design.

In conclusion, there was no difference in the incidence of complications between the pediatric and adult patients after scoliosis corrective surgery, but there was a difference in the correlation factors of the occurrence of complications between the 2 groups. In all ages, the larger the pre-operative Cobb angle, the increase in operating time, duration of anesthesia, and required amounts of intra-operative red blood cell transfusions which resulted in a higher incidence of post-operative complications. In the adults, a pre-operative deteriorated pulmonary function increased the incidence of complications; and in the pediatric patients, comorbidities affected a patient's outcome.

\section{References}

1. Wazeka AN, DiMaio MF, Boachie-Adjei O. Outcome of pediatric patients with severe restrictive lung disease following reconstructive spine surgery. Spine (Phila Pa 1976) 2004; 29: 528-34.

2. Gambrall MA. Anesthetic implications for surgical correction of scoliosis. AANA J 2007; 75: 277-85

3. Carreon LY, Puno RM, Lenke LG, Richards BS, Sucato DJ, Emans JB, et al. Non-neurologic complications following surgery for adolescent idiopathic scoliosis. J Bone Joint Surg Am 2007; 89: 2427-32.

4. Kang GR, Suh SW, Lee IO. Preoperative predictors of postoperative pulmonary complications in neuromuscular scoliosis. J Orthop Sci 2011; 16: 139-47.

5. Takahashi S, Delecrin J, Passuti N. Surgical treatment of idiopathic scoliosis in adults: an age-related analysis of outcome. Spine (Phila Pa 1976) 2002; 27: 1742-8.

6. Fu KM, Smith JS, Polly DW, Ames CP, Berven SH, Perra JH, et al. Morbidity and mortality associated with spinal surgery in children: a review of the Scoliosis Research Society morbidity and mortality database. J Neurosurg Pediatr 2011; 7: 37-41.

7. Yadla S, Maltenfort MG, Ratliff JK, Harrop JS. Adult scoliosis surgery outcomes: a systematic review. Neurosurg Focus 2010; 28: E3.

8. Taggart NW, Shaughnessy WJ, Stans AA, McIntosh AL, Driscoll DJ. Outcomes of spinal fusion in children with congenital heart disease. J Pediatr Orthop 2010; 30: 670-5.

9. Sansur CA, Smith JS, Coe JD, Glassman SD, Berven SH, Polly DW Jr, et al. Scoliosis research society morbidity and mortality of adult scoliosis surgery. Spine (Phila Pa 1976) 2011; 36: E593-7.

10. Chen Z, Yi H, Li M, Wang C, Zhang J, Yang C, et al. Associations between body mass and the outcome of surgery for scoliosis in Chinese adults. PLoS One 2011; 6: e21601.

11. Anderson PR, Puno MR, Lovell SL, Swayze CR. Postoperative respiratory complications in non-idiopathic scoliosis. Acta Anaesthesiol Scand 1985; 29: 186-92.

12. Nachemson A. A long term follow-up study of non-treated scoliosis. Acta Orthop Scand 1968; 39: 466-76.

13. Patil CG, Santarelli J, Lad SP, Ho C, Tian W, Boakye M. Inpatient complications, mortality, and discharge disposition after surgical correction of idiopathic scoliosis: a national perspective. Spine J 2008; 8: 904-10.

14. Gibson PR. Anaesthesia for correction of scoliosis in children. Anaesth Intensive Care 2004; 32: 548-59.

15. Modi HN, Suh SW, Yang JH, Cho JW, Hong JY, Singh SU, et al. Surgical complications in neuromuscular scoliosis operated with posterior- only approach using pedicle screw fixation. Scoliosis 2009; 4: 11.

16. Udink ten Cate FE, van Royen BJ, van Heerde M, Roerdink D, Plotz FB. Incidence and risk factors of prolonged mechanical ventilation in neuromuscular scoliosis surgery. J Pediatr Orthop B 2008; 17 : 203-6.

17. Yuan N, Skaggs DL, Dorey F, Keens TG. Preoperative predictors of prolonged postoperative mechanical ventilation in children following scoliosis repair. Pediatr Pulmonol 2005; 40: 414-9.

18. Marsh A, Edge G, Lehovsky J. Spinal fusion in patients with Duchenne's muscular dystrophy and a low forced vital capacity. Eur Spine J 2003; 12: 507-12.

19. Harper CM, Ambler G, Edge G. The prognostic value of preoperative predicted forced vital capacity in corrective spinal surgery for Duchenne's muscular dystrophy. Anaesthesia 2004; 59: 1160-2.

20. Zhang JG, Wang W, Qiu GX, Wang YP, Weng XS, Xu HG. The role of preoperative pulmonary function tests in the surgical treatment of scoliosis. Spine (Phila Pa 1976) 2005; 30: 218-21.

21. Vedantam R, Crawford AH. The role of preoperative pulmonary function tests in patients with adolescent idiopathic scoliosis undergoing posterior spinal fusion. Spine (Phila Pa 1976) 1997; 22: 2731-4.

22. Smith BG, Hakim-Zargar M, Thomson JD. Low body mass index: a risk factor for superior mesenteric artery syndrome in adolescents undergoing spinal fusion for scoliosis. J Spinal Disord Tech 2009; 22: 144-8.

23. Hassan N, Halanski M, Wincek J, Reischman D, Sanfilippo D, Rajasekaran S, et al. Blood management in pediatric spinal deformity surgery: review of a 2-year experience. Transfusion 2011; 51: 2133-41.

24. Bitan F, Rigault P, Houfani B, Sidi D, Padovani JP, Merckx J, et al. Scoliosis and congenital heart diseases in children. Apropos of 44 cases. Rev Chir Orthop Reparatrice Appar Mot 1991; 77: 179-88.

25. Coran DL, Rodgers WB, Keane JF, Hall JE, Emans JB. Spinal fusion in patients with congenital heart disease. Predictors of outcome. Clin Orthop Relat Res 1999; 364: 99-107.

26. Wongprasartsuk P, Stevens J. Cerebral palsy and anaesthesia. Paediatr Anaesth 2002; 12: 296-303.

27. Sunohara N, Takagi A, Nonaka I, Tomi H, Satoyoshi E. Scoliosis and malignant hyperthermia. Rinsho Shinkeigaku 1984; 24: 1149-54.

28. Hoenemann CW, Halene-Holtgraeve TB, Booke M, Hinder F, Daudel F, Reich A, et al. Delayed onset of malignant hyperthermia in desflurane anesthesia. Anesth Analg 2003; 96: 165-7.

29. Mendiratta A, Emerson RG. Neurophysiologic intraoperative monitoring of scoliosis surgery. J Clin Neurophysiol 2009; 26: 62-9.

30. Pelosi L, Stevenson M, Hobbs GJ, Jardine A, Webb JK. Intraoperative motor evoked potentials to transcranial electrical stimulation during two anaesthetic regimens. Clin Neurophysiol 2001; 112: 1076-87. 